\title{
A CIÊNCIA DA INFORMAÇÃO NA ÓTICA DA PUC-MINAS
}

\author{
Ana Maria P. CARDOSO \\ Humberto Torres Marques NETO \\ Eleonora Bastos HORTA \\ Manoel Palhares MOREIRA \\ Maria Helena Andrade MAGALHÃES 1
}

\begin{abstract}
RESUMO
Relata a concepção politico pedagógica do curso de graduação em Ciência da Informação na PUC-Minas. O curso pretende formar profissionais com conhecimentos do universo informacional, enfocando os fatores sociais e humanos presentes no ciclo de comunicação da informação e as tecnologias disponiveis para geração, organização e disseminação da informação para os diversos usuários. Define o perfil do profissional a ser formado e analisa resultados alcançados desde sua implantação em fevereiro de 2000.
\end{abstract}

Palavras-chave: Ciência da Informação; Ensino.

\begin{abstract}
Report on the political-pedagogical conception of the undergraduate course on Information Science at PUC-Minas (Minas Gerais, Brazil). The course aims at graduating professionals with knowledge on the informational universe, focusing on the social and human factors that are present in the cycle of communication of information, and the available technologies for generating, organizing and disseminating information for several users. It defines the profile of the professional to be trained and analyses results accomplished since its implementation in February 2000.
\end{abstract}

Key words: Information Science; Education Program.

\section{O PONTO DE PARTIDA}

É fato reconhecido que a informação vem se tornando, cada vez mais, importante na organização da sociedade contemporânea: dos negócios à ciência, da escola à vida cotidiana, transporte, alimentação, saúde, lazer, direitos, tributos, segurança, turismo - a lista é infindável. Em todas as esferas da vida a humanidade carece mais e mais de conhecimento para produzir e se desenvolver. Esta característica corresponde ao que muitos autores denominam "Sociedade da Informação".
No campo da análise sociológica, alguns autores defendem que a explosão informacional representa uma nova forma de organização social, um tempo novo em que as relações sociais estariam marcadas pela velocidade de transmissão propiciada pelos aparatos tecnológicos e pelo aparecimento da dimensão virtual substituindo a percepção concreta do aqui/agora. Também se apregoa que essa velocidade, bem como o deslocamento espacial, permitidos pelas tecnologias da informação (basicamente a telemática e a informática)

1. Membros da comissão nomeada pelo Reitor para elaboração do projeto de criação do curso de graduação em Ciência da Informação na PUC-Minas. 
estariam exacerbando tanto a exclusão social daqueles que não pertencem à comunidade de "infonautas", quanto a exploração individual através do teletrabalho ou da produtividade medida pelo tempo da máquina digital. Como em outros momentos registrados pela história das técnicas, não há um consenso: se para alguns é o inferno, para outros, é o paraíso. Independentemente de qualquer interpretação, é inegável a inserção da tecnologia na vida de todo ser humano.

Nas esferas pública e privada, o acesso a informações analisadas e organizadas passou a ser exigência estratégica para o sucesso dos negócios e das políticas. Ter informação disponível e trabalhada é vital para a gestão dos negócios, da empresa, da cidade, do Estado. As possibilidades de participação social, de cidadania e até mesmo da democracia, se alicerçam no direito à informação, ao mesmo tempo em que as facilidades trazidas pelas tecnologias da informação permitem avançar em projetos até agora impensados.

Entretanto, tem sido comum encontrar importantes propostas políticas e também estratégias empresariais ancoradas na confiabilidade das soluções tecnológicas que fracassam pela incapacidade de se conseguir a articulação de ações tão somente por meio de máquinas interconectadas. Informar-se é um processo humano de adquirir conhecimento através da ação de comunicar-se, o que na atualidade atingiu níveis elevados de complexidade e rapidez. A apreensão e interpretação deste fenômeno social, na busca de melhor utilização do seu potencial, exige o consórcio de muitos saberes, aliando ao conhecimento do homem o conhecimento da técnica.

Neste contexto se constituiu como campo de conhecimento a Ciência da Informação, que é, por sua própria natureza, interdisciplinar, pois pretende estabelecer a interseção entre o saber sobre a sociedade e o saber sobre a tecnologia: processos, fluxos e relações. Ao ocupar-se em "esclarecer um problema social concreto, o da informação, voltada para o ser social que procura a informação (...) torna-se uma ciência social rigorosa, sob o efeito tanto de uma demanda social crescente quanto de novos objetivos sociais e importantes avanços econômicos".

Esta ciência social complementa-se com o conhecimento rigoroso da tecnologia, tendo como objeto:

"a análise dos processos de construção, comunicação e uso da informação (portanto sociais) e a concepção dos produtos e sistemas que permitem sua construção, comunicação, armazenamento e uso (portanto tecnológicos)"

"Difere de outras abordagens também voltadas ao objeto informação, sobretudo por se instituir sobre uma base não apenas interdisciplinar, mas de interface entre o saber tecnológico e o saber social" ${ }^{\text {2 }}$.

Estas palavras, retiradas do texto da proposta de criação do Curso de Ciência da Informação na PUC-Minas ${ }^{3}$, traduzem a concepção epistemológica que norteou as discussões e deliberações que culminaram no modelo de curso relatado a seguir.

\section{O CENÁRIO}

No documento "Mestrado no Brasil - a situação e uma nova perspectiva", a comissão de especialistas indicados pela CAPES, para análise do modelo vigente da pós-graduação no país, afirma de forma muito precisa que "as mudanças tecnológicas e as correntes de transformações econômico-sociais têm demandado profissionais com perfis de especialização distintos dos tradicionais".

2. LE COADIC, Y. Ciencia da Informação. Brasília: Briquet de Lemos, 1996.

3. PONTIFICIA UNIVERSIDADE CATÓLICA DE MINAS GERAIS. Proposta de criação do curso de graduação em Ciência da Informação. 1999. (Documento de circulação interna). 
Embora referente a cursos desse nível, a afirmativa reflete e é emblemática da opinião, amplamente disseminada na sociedade - seja nos meios acadêmicos, seja nos segmentos empresariais/industriais - a respeito da defasagem existente entre as propostas do ensino superior e as necessidades sociais a serem atendidas pelos profissionais formados em universidades segundo enfoques específicos e fragmentados.

Comumente se argumenta que o leque de profissões contemplado nos cursos de graduação, embora amplo, não corresponde mais às exigências da realidade contemporânea, trazendo como conseqüência a demanda por cursos de especialização ou mestrado com características profissionalizantes.

Paralelamente a isto, a organização social contemporânea caracteriza-se pelo crescente recurso à informação, produzida, armazenada e processada pelas tecnologias de comunicação e informação. Toda atividade econômica trata de atender a interesses de um mercado, de consumidores, fornecedores, distribuidores, ao mesmo tempo em que existe um universo de relacionamentos com o setor público (tributário, monetário, cambial, previdenciário, legal). Qualquer desses ambientes solicita um número crescente de informações que serão utilizadas na produção de diagnósticos, pareceres, cenários e projeções.

Discute-se muito a respeito das necessidades e demandas sociais por um profissional com perfil decorrente da formação situada na interseção da técnica com o humanismo, de forma a aliar sensibilidade social à eficiência tecnológica, reunindo o que antes se apresentava fragmentado na preparação dos atores de um mundo de seres humanos que não podem mais prescindir das tecnologias.

\section{A META ALMEJADA: \\ O PERFIL PROFISSIONAL}

Para ser considerado um profissional, o trabalhador precisa apresentar duas características fundamentais:

a. possuir conhecimento especializado;

b. colocar este conhecimento a serviço de outras pessoas.
No momento histórico atual, em que a sociedade se move em meio a uma verdadeira avalanche de informações, é preciso definir o papel social do profissional que lida com os registros do conhecimento: quais são as suas funções? $\mathrm{O}$ que o distingue de outros profissionais? Quais são sua ética e suas responsabilidades? Como deve ser educado?

Seja qual for sua denominação específica, o profissional da informação tem como objeto de conhecimento e de trabalho o próprio conhecimento: é o intermediário entre aqueles que o produzem e os que vão utilizá-lo, contribuindo dessa forma para a alteração do repertório cognitivo das pessoas e para o processo de influência das mentes humanas. Cada demanda de informação constitui uma situação única e especial, muitas vezes marcada por ambigüidades, incertezas e para a qual não existe uma solução clara e previamente definida; pelo contrário, as possibilidades de solução podem ser variadas e, não raro, envolvem conflitos de valor, até mesmo em relação aos objetivos do próprio solicitante.

Satisfazer uma demanda de informação não é simplesmente um problema técnico; mais do que isso, requer do profissional capacidade de interpretação das questões colocadas pelo usuário; discernimento e julgamento das alternativas mais adequadas e tomada de decisão.

Para o bom desempenho de suas funções, o profissional da informação necessita de sólidos conhecimentos, envolvendo:

a. o universo informacional, constituído pelo conjunto das diferentes fontes, estruturas, formas de expressão e de registro do conhecimento humano;

b. todo o ciclo de comunicação da informação, que tem início com a geração de dados, passa por formas de registro, controle, organização e disseminação, visando à utilização do conhecimento adquirido, o que vai realimentar todo o processo e dar origem a novos fluxos informativos;

c. os fatores humanos, sociais, econômicos e culturais que exercem influências decisivas e inquestionáveis, em cada etapa do processo de comunicação da informação; 
d. os usuários da informação: seu perfil, suas necessidades informacionais, seus comportamentos de busca e de uso da informação, para que possa não só atender adequadamente as demandas feitas, como também, e principalmente, antecipá-las;

e. a tecnologia da informação, considerando-se não só o instrumental tecnológico propriamente dito - máquinas eletrônicas e outros equipamentos disponíveis que facilitam e agilizam todo o processamento da informação - como também o conjunto de conceitos relativos à organização da informação: análise, classificação, indexação, resumo, formatação, avaliação, dentre outros - que vão guiar os processos de seleção, tratamento, armazenamento e disseminação da informação, direcionando a aplicação daquele mesmo instrumental.

Toda profissão deve ter na ética um de seus pilares básicos e não poderia ser diferente, em se tratando de um profissional do conhecimento. Situações de busca/provisão de informações envolvem uma relação de poder (entendido aqui como habilidade para produzir um efeito desejado) que favorece o profissional, isto é, aquele que conhece as fontes de informação, as formas de acesso, organização e controle, bem como as tecnologias apropriadas para sua obtenção. Com a responsabilidade social de ser um intermediário entre fonte e usuário da informação, o profissional deve pautar sua atuação em sólidos princípios éticos e nunca perder de vista o fio condutor que deve orientar seu trabalho, qual seja: proporcionar a cada usuário a informação mais correta e atualizada, obtida da fonte mais íntegra e confiável, organizada da forma mais apropriada, em espaço de tempo adequado e por um preço razoável, justificado pelo uso (quando se tratar de serviços pagos) para aquele usuário que nele depositou confiança e que, quase sempre, vai utilizar a infor- mação requerida como base para trabalhos e decisões importantes.

Estas devem ser as características norteadoras para a graduação de um profissional em Ciência da Informação, permitindo-lhe atuar em ambientes organizacionais públicos ou privados, regionais, nacionais ou internacionais, de cunho científico, cultural, empresarial ou assistencial, reunindo características que, na atualidade, quando encontradas, o são em profissionais com longa e eclética trajetória ocupacional, geralmente pós-graduados.

\section{O CURSO (OU MELHOR O PERCURSO)}

Com o intuito de expandir o leque de oferta de cursos e, conseqüentemente, incorporar mais um campo do saber às discussões do cotidiano da Universidade, o Reitor da PUC-Minas instituiu, ao final do segundo semestre letivo de 1998, comissão ${ }^{4}$ para elaborar o Projeto de Implantação do Curso de Ciência da Informação visando à formação de um profissional com as habilidades adequadas para enfrentar os desafios postos pelo advento da explosão informacional desse final de milênio.

A complexidade e a responsabilidade de construção de um percurso de formação acadêmica que o profissional da informação deveria seguir em seus quatro anos de graduação, demandaram muitos meses de estudo e trabalho. Sendo assim, os trabalhos se estenderam até o mês de setembro de 1999, quando o projeto do curso foi submetido e aprovado pelo Conselho de Ensino e Pesquisa da PUC-Minas, com sua implantação autorizada para o primeiro semestre do ano de 2000.

Devido à característica interdisciplinar da proposta e em decorrência das semelhanças de campos do saber que compartilham desafios e questionamentos, o curso de Ciência da Informação passou a fazer parte da estrutura organizacional do Instituto de Informática, que até então oferecia apenas o curso de Ciência da Computação.

4. É interessante destacar que todos os membros da comissão, embora oriundos de diferentes cursos de graduação (Biblioteconomia, Computação, Economia e Engenharia) tem pós-graduação em Ciência da Informação. 
Um curso de graduação deve apontar pelo menos um caminho mínimo que o estudante deve percorrer, e conseqüentemente superar, para atingir um estágio que viabilize o início do exercício de uma profissão. Esse estágio se caracteriza pelo tipo de comportamento que o profissional tem ao se deparar com um desafio de sua área de saber, ou seja, pelas habilidades que utiliza para desvelar um enigma do seu tempo social.

Com uma formação fortemente centrada na tecnologia informática e nas ciências sociais, nos aspectos em que ambas se aproximam e geram interfaces, ao estudar o fenômeno informação, o profissional que se pretende formar deverá saber utilizar o conhecimento de informática em suas particularidades ferramentais e potencialidades de processamento, armazenagem e recuperação de dados/informação, e capacitar-se a opinar, orientar e decidir sobre alternativas tecnológicas.

No que se refere às técnicas e procedimentos de análise de conteúdo, indexação, classificação (definição de categorias), pesquisa documental e bibliográfica, o saber da Biblioteconomia e áreas circunvizinhas permitirá o destaque das especificidades do produto informacional.

Aos conhecimentos específicos da ciência da informação e ao domínio da tecnologia da informação mais avançada, precisam ser incorporados princípios teóricos e conceitos advindos de diferentes disciplinas das ciências sociais e humanas, na formação de um profissional participante do processo de comunicação com seres humanos, tão semelhantes em suas carências de informação e ao mesmo tempo tão diferentes, em suas necessidades específicas. Assim, através de conhecimentos proporcionados pelas ciências cognitivas, deverá habilitar-se a compreender: o processo do conhecer, os aspectos humanos envolvidos na produção, busca e utilização de informações, os fatores intervenientes no processo comunicativo e na interação homem/máquina.

Além disso, o profissional não pode perder de vista o contexto histórico, político, social e cultural de sua atuação, consciente de que é uma peça importante na construção e desenvolvimento da sociedade da informação. A percepção da informação enquanto fenômeno social, imbricada no conteúdo das ciências sociais, permitirá ao profissional entender a informação no cenário econômico-político-cultural contemporâneo, permitindo-lhe a necessária sensibilidade para definição de estratégias e ações contextualizadas na organização e na sociedade.

O projeto político-pedagógico do curso contempla a interdisciplinaridade como característica fundante: o objeto informação estudado e trabalhado segundo perspectivas específicas de cada campo de saber, mas constituindo-se em elemento articulador da formação acadêmica. O foco de estudo desloca-se das especificidades de acervos e de registros da produção intelectual e volta-se para o processo de produção do conhecimento instrumentalizado pela comunicação e uso da informação quer seja dos indivíduos (sujeitos cognoscentes) ou das organizações (coletivos inteligentes).

O curso de graduação em Ciência da Informação da PUC-Minas pretende situar-se na interface dos saberes das ciências sociais e da tecnologia informática, incorporando e articulando experiências consolidadas em outros campos já tradicionais como: Biblioteconomia, Computação, Administração, Economia, Psicologia Social e Comunicação com aquelas de áreas mais recentes, como as várias disciplinas das Ciências Cognitivas, a Sociologia do Conhecimento e a Cibernética.

O desenvolvimento de habilidades de um profissional passa pelo seu envolvimento e questionamento dos conteúdos de um determinado campo do conhecimento. Tais conteúdos, ou textos que veiculam o conhecimento, normalmente são organizados em disciplinas. Como os cursos de graduação da PUC-Minas estão organizados em semestres letivos e períodos, o curso de graduação em Ciência da Informação seguiu o mesmo modelo. Tratava-se de compor a grade de disciplinas para formar um período, e de definir o encadeamento dos períodos de forma a estabelecer uma correlação que conduzisse à formação do sujeito em seu processo de 
conhecer e adquirir habilidades. Dessa forma, foi definido um eixo determinante das ações de cada período (semestre) do curso, de tal sorte que caracterizasse cada momento da formação do profissional da informação. Assim:

- O primeiro período tem como objetivo a "Formação do sujeito acadêmico" e é composto por disciplinas que introduzem o aluno na área de conhecimento e nas especificidades da formação universitária, capacitando-o a enfrentar os desafios dos conteúdos que serão trabalhados no decorrer do curso;

- O eixo aglutinador do segundo período é a discussão sobre "Conhecimento e Informação", possibilitando ao aluno desenvolver habilidades necessárias para lidar com questões advindas da relação, nem sempre amistosa, entre a informação e o conhecimento;

- Para lidar com a informação é extremamente importante saber organizá-la; por isso o eixo do terceiro período é a "Organização de Informação";

- O quarto período enfoca as "Instituições sociais e a informação" pois o homem como ser social que é, cria grupos e os institucionaliza para superar os seus desafios;

- Os fundamentos teóricos da informação e os sistemas de informação conduzem o quinto período do curso, sob o tema "Teoria e sistemas de informação";

- Como a informação de valor é aquela que pode ser disseminada e usada em diversos contextos, o profissional da informação deve ter habilidades que criem condições para isso. Dessa forma, o sexto e o sétimo período do curso recebem o nome de "Disseminação e uso da informação I e II", respectivamente;

- Depois de três anos e meio na Universidade, o aluno do curso de Ciência da Informação encerra o seu percurso refletindo e discutindo a sua prática profissional: "Ati- vidades Profissionais" constitui o eixo do $8^{\circ}$ período.

Da mesma forma, buscou-se organizar o conjunto das disciplinas de acordo com os núcleos de formação, por exemplo:

- Formação profissional: organização, recuperação, disseminação e uso da informação; análise de sistemas de informação, bancos de dados, redes de informação;

- Formação social e humanística: história econômica e da tecnologia, produção social do conhecimento, informação e processo cognitivo, informação e linguagem, fundamentos teóricos e sociais da Ciência da Informação, filosofia;

- Formação gerencial: métodos e processos administrativos, informação contábil e gerencial, informação e administração pública, informática nas organizações, organizações baseadas no conhecimento, economia brasileira.

O curso é integralizado com 159 créditos, perfazendo o total de 2.895 horas/aula, das quais 2.385 teóricas e 510 práticas, incluindo aulas em laboratórios, estágios e atividades extra-classe $\mathrm{e}^{5}$.

A figura a seguir demonstra a distribuição percentual dos conteúdos estudados, segundo as áreas temáticas de origem.

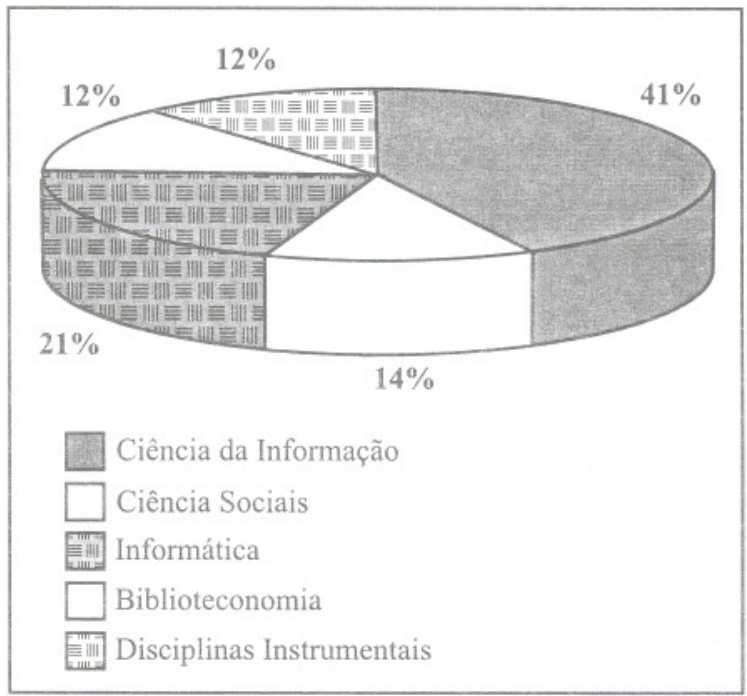

5. Informações sobre a grade curricular, encadeamento de disciplinas e carga horária podem ser acessadas no site www.inf.pucminas. br/ci 


\section{OBSERVAÇÕES DA TRAJETÓRIA}

O curso de graduação em Ciência da Informação da PUC-Minas, em agosto de 2001, encontra-se ainda em seu segundo ano de funcionamento, com quatro turmas em processo de formação, devendo completar, ao final do corrente ano, a metade de seu percurso. De todo modo, muitas observações já podem ser feitas acerca da caminhada.

Sem dúvida alguma, o principal desafio que o curso enfrenta decorre justamente de sua característica principal: a novidade. O fato de ser uma proposta absolutamente inovadora em termos de curso de graduação, faz com que a equipe e a universidade tenham que se desdobrar para torná-la conhecida pela sociedade. Neste sentido foram definidas estratégias direcionadas ao público estudantil (colégios, cursinhos, orientadores vocacionais) ao mercado de trabalho (empresários, profissionais da área, organizações públicas e do terceiro setor) e às entidades formadoras de opinião (instituições de ensino, veículos de comunicação, entidades classistas). A credibilidade e a legitimidade social da PUC-Minas conferem ao curso o respeito que lhe abre portas e foruns de exposição. Desta forma a receptividade apresenta significativo crescimento, especialmente entre profissionais que atuam na área da informação empresarial e que percebem o potencial do jovem que estará formado em pouco tempo. Este tipo de interlocução tem gerado importantes parcerias que, ao mesmo tempo em que criam espaços para atuação/aprendizado dos alunos, promovem a divulgação do curso.

Um entrave que é comumente citado acerca do curso diz respeito à denominação e registro do profissional graduado em Ciência da Informação pela PUC-Minas. A este respeito a PUC-Minas foi interpelada pelo Conselho Regional de Biblioteconomia $-6^{\mathrm{a}}$ região, quando da elaboração do projeto, antes mesmo de sua aprovação pelo Conselho de Ensino e Pesquisa da Universidade. O curso de Ciência da Informação, aqui descrito, difere dos demais cursos existentes no país. Neste sentido, não tem pretensões de obter o reconhecimento dos órgãos de registro profissional existentes em condições similares à dos profissionais graduados em cursos com outras especificidades; assim como também não pode aspirar a um título para o seu graduado idêntico ao dos graduados pelos outros cursos.

Também nesta direção, os 42 anos de tradição e reconhecimento social da PUC-Minas, em âmbito nacional e internacional, permitem-lhe ousar e inovar. A experiência do curso-irmão do Instituto de Informática da PUC-Minas, o curso de Ciência da Computação, fornece elementos para se enfrentar este desafio com coragem. Acredita-se que o exercício profissional do Bacharel em Ciência da Informação (título oficial que constará dos diplomas) acabará por ser culturalmente assimilado, assim como o foram os computatas, informatas, analistas de sistema, e outras alcunhas mais pelas quais o bacharel em Ciência da Computação é denominado, sem que haja a identificação única formal e legal. Quanto ao registro profissional, o caminho é semelhante - outras profissões igualmente úteis à sociedade também não estão regulamentadas. Apenas a passagem do tempo poderá trazer solução a estas questões.

Ainda um último ponto merece ser destacado. Trata-se da dificuldade operacional de implementar uma proposta que foge ao padrão instituído. Cada nova disciplina que é ofertada requer reuniões e articulações que garantam a fidelidade à proposta original. O caráter interdisciplinar demanda professores que assumam a proposta epistemológica e político-pedagógica do curso como "profissão de fé" - o que nem sempre é fácil. O corpo docente do curso tem sido recrutado preferencialmente entre mestres e doutores da área ou de áreas correlatas e que possam contribuir para seu aprimoramento. Apesar das dificuldades e percalços, o desafio de criar e de inventar caminhos é contagiante na equipe, o que pode ser decodificado como indicador do potencial de geração de respostas e soluções para as demandas sociais contemporâneas e a inauguração de novos rumos para as novas gerações.

Sabemos todos que a Ciência da Informação faz parte de um grande grupo de novas disciplinas 
que, segundo a classificação de Boaventura de Souza Santos ${ }^{6}$, compõem um "paradigma emergente", ou seja, pautam-se por temáticas, problemas e métodos diversos daqueles da ciência cartesiana clássica. Em função disto, trata-se de um campo ainda em formação, para o qual concorrem muitos saberes, diversas perspectivas teóricas ${ }^{7}$ defendidas por estudiosos de origem vária, e que vem se consolidando no sentido do exercício da prática para a sistematização teórica.
Sendo assim, o modelo de curso desenhado e implementado pela PUC-Minas almeja por prestar um serviço relevante para a sociedade, formando profissionais capacitados a entender e solucionar problemas relacionados com o fenômeno contemporâneo da informação e, ao mesmo tempo, tem a expectativa de poder contribuir pelos seus questionamentos, reflexões, pesquisas e experiências para o crescimento e desenvolvimento da área de Ciência da Informação no nosso país.

6. SANTOS, B.S. Um discurso sobre as ciências. Porto: Afrontamento, 1996.

7. A este respeito, são emblemáticos os textos e debates produzidos para os colóquios de Tampere, que se tornaram marcos importantes para a constituição de uma teoria da Ciência da Informação. (Cf: VAKKARI,P. e CRONIN,B. Conceptions of library and information science: historical, empirical and theoretical perspectives. Londres: Taylor Graham, 1992.) 